\title{
The effect of composite floor on the robustness of a steel self- centering MRF under column loss
}

\author{
C.A. Dimopoulos ${ }^{a}$, F. Freddi ${ }^{b}$, T.L. Karavasilis ${ }^{c}$ and G. Vasdravellis ${ }^{\mathrm{d} *}$ \\ ${ }^{a}$ University of Warwick, United Kingdom \\ bUniversity College London, United Kingdom \\ 'University of Southampton, United Kingdom \\ ${ }^{\mathrm{d}}$ Heriot-Watt University, United Kingdom \\ *Corresponding author, e-mail address: G.Vasdravellis@hw.ac.uk
}

\begin{abstract}
This paper presents the numerical assess of the robustness of a seismic-resistant steel building with self-centering moment resisting frames against progressive collapse. The numerical analyses were carried out using a 3D model developed in ABAQUS. The 3D model considers the effect of the composite slab, where composite beams and their shear connectors were modeled with a combination of shell, beam and nonlinear connector elements. All the beam-column and beam-to-beam connections were modeled using nonlinear connector elements with appropriate failure criteria, calibrated against previous experimental results. The self-centering moment resisting frame where a sudden column loss was simulated was modelled using 3D solid elements to accurately capture its local and global nonlinear behavior. Quasi-static nonlinear analyses were carried out to identify all possible failure modes and to investigate the effect of the floor slab on the overall progressive collapse resistance. Nonlinear dynamic analyses were also carried out to predict the true dynamic response and evaluate the acceptance criteria of current building design guidelines.
\end{abstract}

Keywords: Progressive collapse; Self-Centering Moment Resisting Frames; Robustness.

\section{Introduction}

Conventional seismic-resistant structures, such as steel moment-resisting frames (MRFs), are designed to experience significant inelastic deformations under strong earthquakes [1]. Inelastic deformations result in damage of structural members and residual interstory drifts, which lead to high repair costs and disruption of the building use or occupation. The aforementioned socio-economic risks highlight the need for widespread implementation of minimal-damage structures, which can reduce both repair costs and downtime. Amongst others, steel frames equipped with self-centering beamcolumn connections with post-tensioned (PT) high strength bars [2], [3] demonstrated their superior seismic performance, i.e., in minimizing the damage in the main structural components and in providing self-centering capability even under strong earthquakes.
However, specialization of the structure in order to improve the seismic performances should not affect their capability to resist other types of hazard and multi-hazard considerations are required [4], [5].

Amongst others, man-made hazards deriving from events such as fire, explosions or impact gained the attention of many researchers in the last decades because of the possibility of progressive collapse [6]. Progressive collapse of a structure occurs when the failure of a structural component, leads to the collapse of the surrounding members, promoting additional or even global collapse.

Despite the relatively large body of research on the seismic behavior of self-centering moment resisting frames (SC-MRFs), their robustness under a column loss scenario is not thoroughly studied. SC-MRFs are placed at the perimeter of a building as lateral force resisting system and, hence, they are prone to accidental 
events that could produce the loss of one or more columns. Previous research on robustness of PT steel frame buildings focused on their 2D behavior only [7]. The present paper focuses on the robustness of SC-MRFs under a column removal scenario accounting also for the contribution of the 3D membrane effects of the slab based on 3D finite element models developed in ABAQUS [9].

\section{Prototype Building}

A 5-story SC-MRF using PT connections with web hourglass shape steel pins (WHPs) [3] is used as the prototype building. The plan view and elevation are shown in Fig. 1.

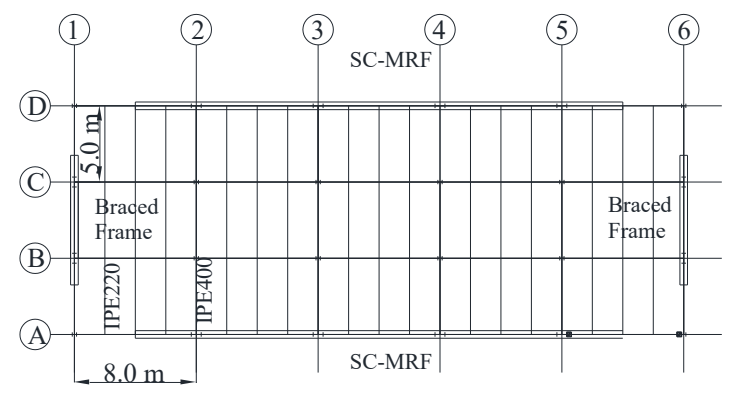

(a)

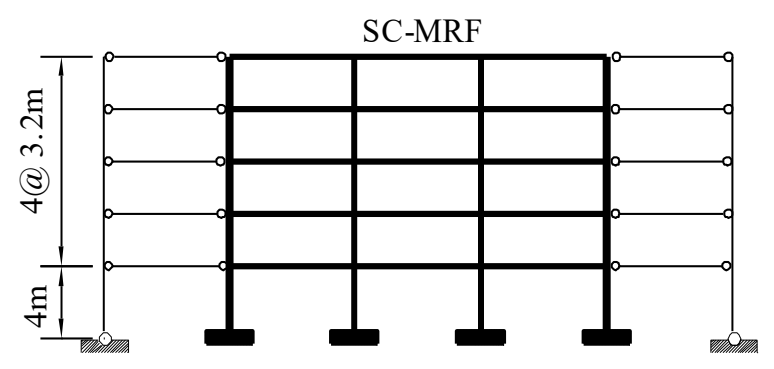

(b)

Fig. 1. a) Plan view, b) elevation view of the prototype building.

The frame uses perimeter SC-MRFs to resist seismic loads, while the interior frames are designed for gravity loads only. Two high strength steel bars located at the mid depth of the beam, one at each side of the beam web, passing through holes drilled on the column flanges. The bars are post-tensioned and anchored to the exterior columns. WHPs are inserted in aligned holes on the beam web and on supporting plates welded to the column flanges. Energy is dissipated through inelastic bending of the WHPs while the self-centering capabilities are ensured by the gap opening mechanism and the presence of the PT bars. More details on the SCMRFs of the case study building are reported in [3], [7] and [8]. The composite slab has a thickness of $120 \mathrm{~mm}$ and is made of $\mathrm{C} 25 / 30$ concrete. A full shear connection is considered for the steel-concrete composite slab. The shear studs used for the composite connection have a diameter and a length of $19 \mathrm{~mm}$ and $100 \mathrm{~mm}$ respectively. An ultimate stress equal to 450 MPa is considered for the determination of the shear stud strength. No shear studs are used in the main beams in 2-5 lines of Fig. 1 because the concrete slab is simply supported to the beams.

\section{Finite element modeling}

The numerical investigation is performed using ABAQUS [9]. The column loss scenarios evaluated in this study simulate the collapse of internal column A3 of one of the two SC-MRF (see Fig. 1). Detailed modeling with the aim of $3 \mathrm{D}$ elements is defined only for the frame that experience the columns loss, while other frames are modeled using 'beam' elements. Only the first floor of the prototype building is modelled with the columns extended up to the half-height of the second floor (Fig. 2). Pinned connections are assigned to the top of the columns to account for the continuity of the columns in order to simulate the presence of the upper stories [10]. The simulation of the column removal is performed in three steps. In the first step, the PT steel bars of the SC-MRF that experiences the column removal are post-tensioned to the required initial force. Two concentrated forces are applied to the two edge columns of the second SC-MRF to simulate the post-tensioning of the PT bars. In the second step, the gravity loads are applied at both the slab and the top of the columns. In the pushdown analyses, the vertical displacement of the 'removed column' is gradually increased up to $2 \mathrm{~m}$. In the case of dynamic analyses, these gravity loads are applied indirectly by changing accordingly the density of the concrete material of the slab.

Columns and beams are modelled using the Timoshenko beam element with linear interpolation (B31). The B31 beam elements allow for transverse shear deformation and finite axial strains and can be used for both slender and stocky beams. The beams, columns and stiffeners of the SC-MRF in the A-line of the prototype building are modelled using 8-node linear brick elements (C3D8), except for a small portion of the columns at their bottom and a small portion of the beams after the web and flange reinforcements where the 8-node brick elements with incompatible modes (C3D8I) are 
considered. These elements are very efficient in capturing local buckling phenomena and are particularly useful in these areas which are susceptible to local buckling. PT bars are modeled using 2-node linear 3-D truss elements (T3D2) and the heads using 8-node linear brick elements (C3D8). PT bars are attached to the heads using multi-points constraints. WHPs are modelled using 3D connectors CONN3D2 with elasto-plastic behavior in the beam longitudinal and gravity directions and rigid behavior in the direction transverse to the beam web and the two of three rotational DOFs excluding the torsional one. Concrete slab is modelled using the 4-node general purpose shell element (S4R). Elements S4R rely on 'reduced integration' and 'hourglass control'. The steel reinforcement in the concrete slab is simulated via the rebar layer option in ABAQUS by considering a number of parameters (e.g., cross-sectional area of the rebar, spacing of rebar in the plane of shell elements, position of the rebar in the shell section thickness direction and angular orientation of the rebar). The mechanical shear connectors are simulated by using the threedimensional connector element CONN3D2. The 3D connectors are assigned with a Cartesian and an ALIGN type of behavior for the translational and the rotational degrees of freedom respectively.

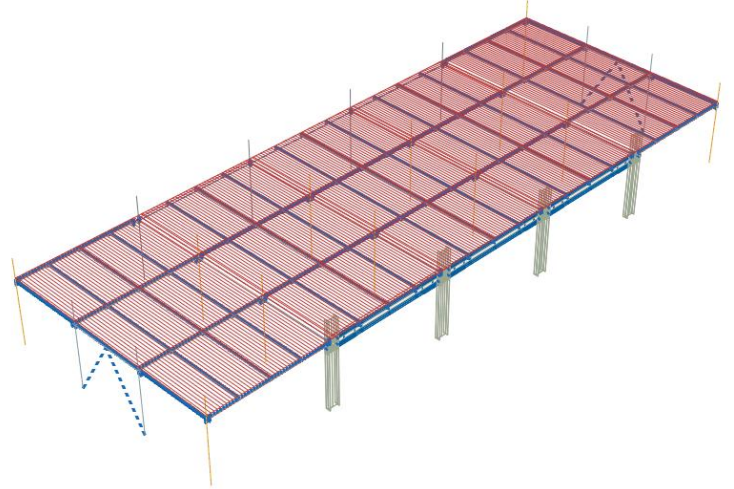

Fig. 2. Numerical model of the first storey of the prototype building.

\section{Validation of the numerical models}

Numerical models are built in ABAQUS to simulate the behavior of the basic structural components i.e., fin plate connections, steelconcrete composite beams, and the SC-MRFs and are validated against experimental results. Accurate modeling of these components is necessary to increase confidence while building the comprehensive model of the prototype building.

\subsection{Validation of the steel-concrete composite beam}

For the validation of the numerical model of the composite beam, the experimental investigation performed by Vasdravellis et al. [11], [12] on a simply supported composite beams under a single point load is considered. Details of the test are reported in Vasdravellis et al. [11], [12]. The steel material of the beam is modeled by an elasto-plastic stress-strain law with hardening. Differently, for the rebars of the slab an elastic perfectly-plastic model is used. The concrete is modeled by using the concrete damage plasticity model in ABAQUS. The concrete stress-strain curve in compression follows a modified Hognestad stress-strain relationship [13] while the modulus of elasticity of the concrete $\mathrm{E}_{\mathrm{c}}$ is taken according to EN19921.1 [14]. For the validation of the numerical model, the experimentally determined tensile strength is considered. For the progressive collapse investigation, the mean tensile strength $\mathrm{f}_{\mathrm{ctm}}$ is taken according to EC2. An idealized behavior in tension is assumed for the concrete with a linear softening and a residual tension strength of $0.1 \mathrm{f}_{\mathrm{ctm}}$ starting at strain equal to 0.05 .

Connector elements (of Cartesian and ALIGN type) connecting the middle surface of the concrete slab to the middle surface of the beam elements are used to model the shear studs (Fig. 3(a)). An elastic-perfectly plastic behavior is assumed for the shear connectors. Experimental strengths are used for the validation of the numerical models of the composite beams. Nominal strengths according to EN1994-1.1 [15] are used in the progressive collapse simulations. Maximum slips obtained from push-out tests are used in the numerical analyses to consider fracture of the studs. Fig. 3(b) shows a comparison between numerical and experimental results for the case of sagging and hogging moment, respectively. The simplified numerical model can capture the sagging and hogging behavior of the composite beam. The larger force capacities exhibited in the hogging moment can be consequence of the idealized behavior that was adopted for the concrete in tension. 


\subsection{Validation of the fin-plate connections}

The experimental results from Thompson [16], described in detail in Main and Sadek [17], have been used to validate the simplified numerical model for the fin plate connection. The fin plate connection is modelled using the component method where at each bolt level a spring is considered having stiffness and strength that described best the combined behavior of the fin plate, the beam web and the bolt (see Fig. 4(a)). The stiffness and strength of these springs are estimated according to EN1993-1.6 [18] while the ultimate deformations according to [17]. Gap-like springs are attached at the beam flange levels to account to contact phenomenon at large displacements. Fig. 4(b) shows the numerical results of a fourbolt fin plate connection accompanied with the corresponding experimental results. A good agreement can be observed for the two cases.

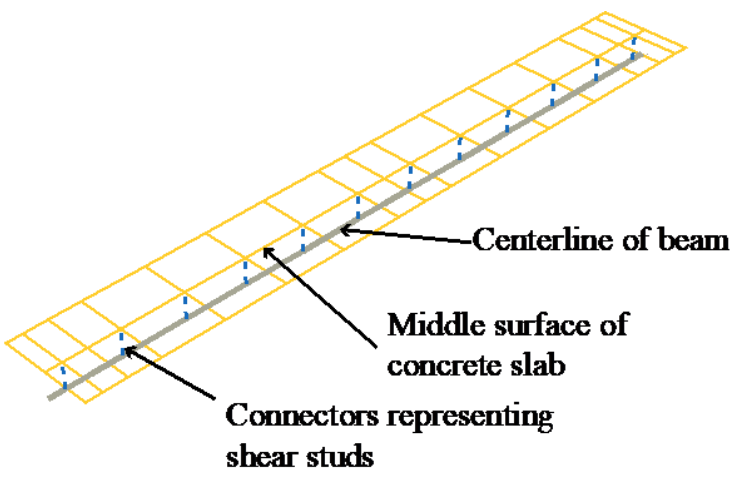

(a)

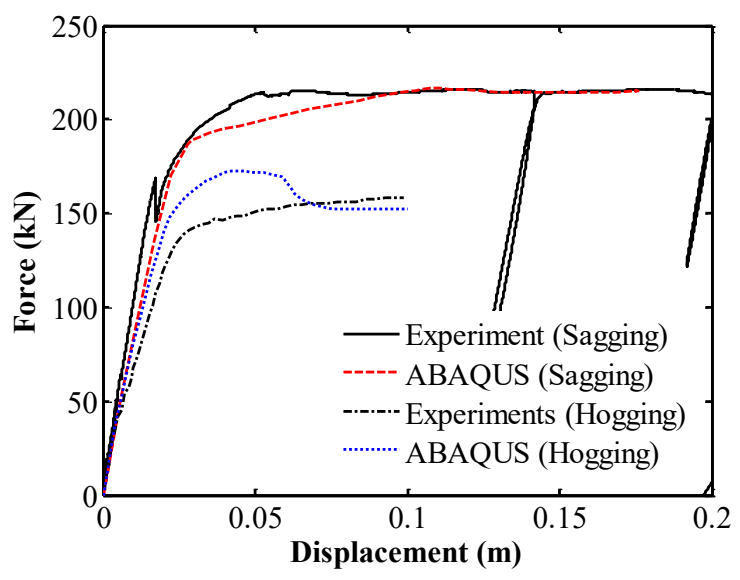

(b)

Fig. 3. a) Numerical model for the composite slab, b) comparison of numerical and experimental results for the composite slab.

\subsection{Validation of the PT connection}

The model of the PT connection with WHPs used in the SC-MRF of the case study building, has been validated by Vasdravellis et al. [19]. Previous results show the capability of this model capturing the cyclic behavior and the local and global failure modes up to large imposed displacements.

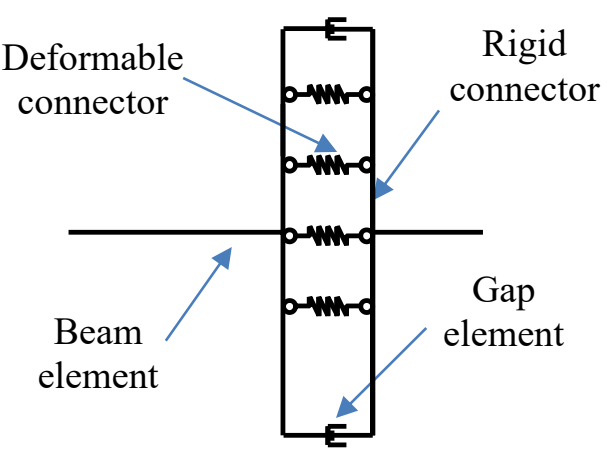

(a)

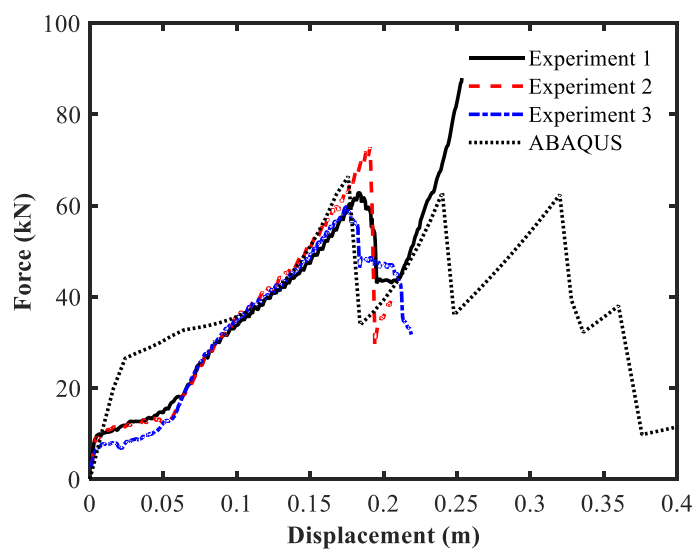

(b)

Fig. 4. a) Fin plate numerical model, b) comparison of numerical and experimental results for the finplate connection.

\section{Quasi-static pushdown analyses for one-column removal scenario}

Nonlinear quasi-static analyses on the firststory model have been performed to identify the failure modes of the building under the removal of the A3 column of the SC-MRFs. The implicit dynamic solver in ABAQUS was used for the quasi-static analyses. To eliminate the inertia effects, the mass density was reduced to the $10^{-3}$ of the initial density. The implicit dynamic solver is used instead of the static general solver because it is more robust in capturing sudden failures, such as the WHP fracture represented by the sudden drop in strength in the load displacement curve. The analysis consisted of 
three steps: a) in the first step the initial PT force was applied by imposing a shortening in the PT bars corresponding to an initial PT force of approximately $1087 \mathrm{kN}$; b) in the second step the gravity loads are applied according to the $1.2 \mathrm{D}+0.5 \mathrm{~L}$ combination, where $\mathrm{D}$ is the dead load and $\mathrm{L}$ is the live load, as prescribed in the UFC guidelines [20]. Gravity loads are simulated by pressure loads on the slabs and concentrated loads for the columns; c) in the third step the fixed base support of the column A3 is removed and the column is pushed down up to $2000 \mathrm{~mm}$. This imposed displacement value corresponds to a connection rotation of $0.25 \mathrm{rad}$ (defined as the imposed displacement over the span of the beam). Three independent numerical models have been built in order to investigate and decouple the contribution of the several components to the overall progressive collapse resistance. These models are 1) a 3D numerical model including the slab, 2) a 3D numerical model of the frame elements and 3) a planar model that includes the SC-MRF only.

An optimized WHP geometry is used in the prototype building in order to achieve higher ductility capacity. This allows to increase the building's robustness, according to Vasdravellis et al. [7]. The ductility of the optimized WHP, defined as the ratio of the fracture displacement $\delta_{\mathrm{f}}$ to the yielding displacement $\delta_{\mathrm{y}}$ is equal to 18 . Consequently, the rotation capacity of the connection is increased to more than $0.2 \mathrm{rad}$.

In Fig. 5 the load-displacement curves obtained from pushdown analyses of the three models of the prototype building are reported. The planar model and the model without slab give practically the same results. Hence, the contribution of the fin-plate connections of the orthogonal beams is negligible to the overall progressive collapse resistance. On the other hand, when the concrete slab is included there is a significant increase in the strength up to $30 \%$. Under large displacement, fracture of some of the WHPs is observed indicated by the sharp drops of the plot. Local buckling at both the web and the flanges immediately after the reinforcement plates at the left side of the beam A23 is observed (see Fig. 6) at the initial stages of the pushdown analysis, however catenary action of the PT bars preserves the integrity of the building (see Fig. 5).

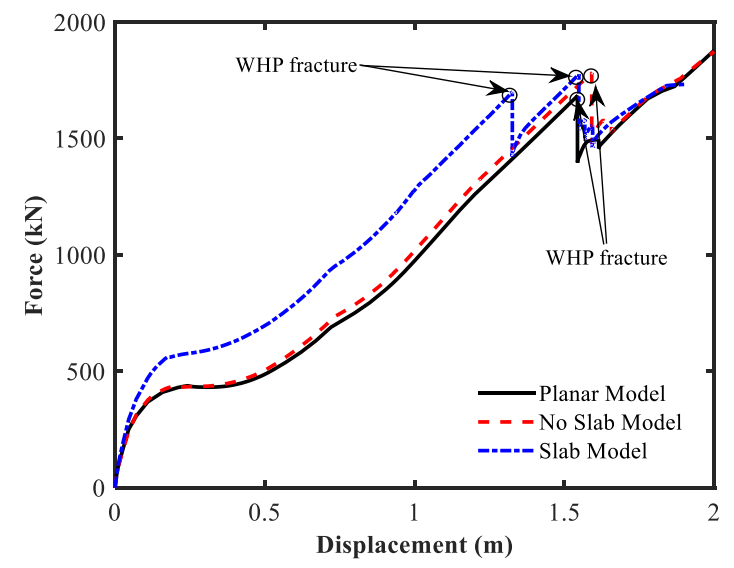

Fig. 5. Pushdown analysis results for the three models (with slab, without slab and planar model).

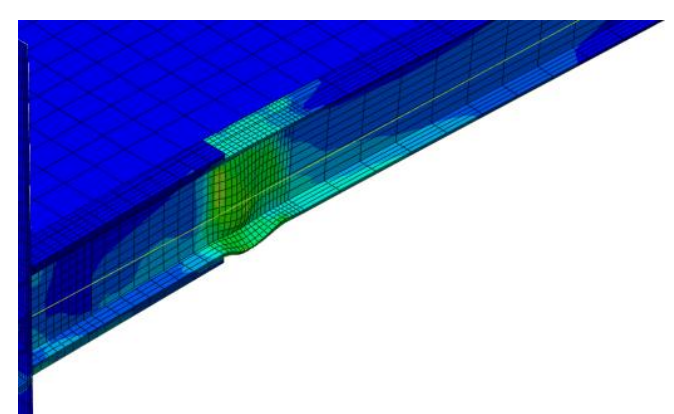

Fig. 6. Buckling of A23 beam after the reinforcement plates at web and bottom flange.

\section{Dynamic analyses for one column removal scenario}

Nonlinear dynamic analyses of the first story of the prototype building are carried out in order to evaluate the contribution of the dynamic effects. The procedure used for the application of the dynamic load is the following: (a) a multiplication factor $\mu$ of the masses is defined as 1 ; (b) the gravitational field $\left(\mathrm{a}_{\mathrm{g}}=9.81 \mathrm{~m} / \mathrm{sec}^{2}\right)$ is defined and the gravitational load combination $1.2 \mathrm{G}+0.5 \mathrm{~L}$ on the slab is simulated by applying an appropriate value of the density of the concrete. At the same time, concentrated loads are applied on the top of the columns to account for the forces transferred by the upper stories of the building. (c) the column A3 is suddenly 'removed' by releasing the support; (d) the analysis is continued until the oscillation of the frame stops and the maximum vertical displacement is recorded. Rayleigh damping is used during the analyses. This procedure is repeated for increasing values of the multiplication factor $\mu$ in order to represent different design situations and to reach increasing displacement values. 
Fig. 7 shows the displacement time histories of the removed column for a number of the magnification factor $\mu$.

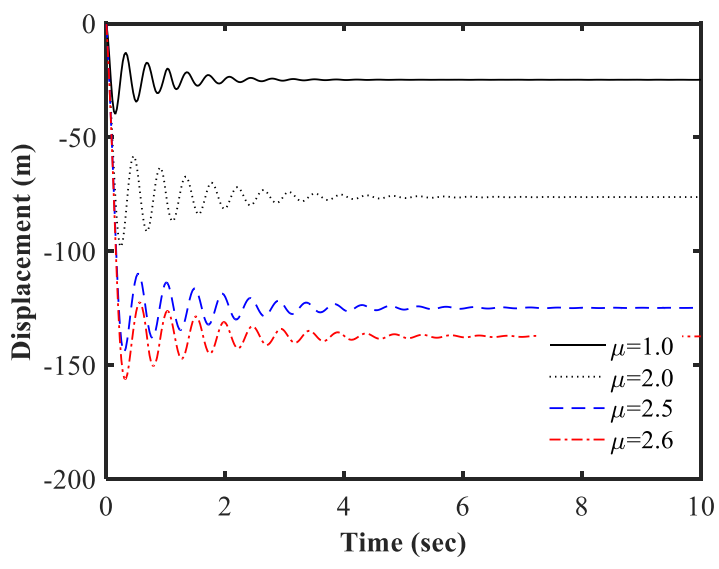

Fig. 7. Time histories of removed column displacement from dynamic analysis.

\section{Assessment of the UFC acceptance criteria}

The Alternate Load Path method according to DoD [20] requires that the structure is be able to bridge over vertical load bearing elements that are notionally removed; if not, the structure should be re-designed or retrofitted. In the nonlinear static procedure, the structure should be able to withstand the actions due to the following load combination above the removed element:

$\mathrm{G}=\mathrm{DIF}(1.2 \mathrm{D}+(0.5 \mathrm{~L}$ or $0.2 \mathrm{~S}))$

where DIF is the dynamic increased factor and to the following combination for floor areas away from the removed column

$$
\mathrm{G}=1.2 \mathrm{D}+(0.5 \mathrm{~L} \text { or } 0.2 \mathrm{~S})
$$

The DIF is defined for a steel framed building as:

$$
\mathrm{DIF}=1.08+0.76 /\left(\theta_{\text {pra }} / \theta_{\mathrm{y}}+0.83\right)
$$

where $\theta_{\text {pra }}$ is the plastic rotation angle for the element, component or connection, and $\theta_{\mathrm{y}}$ is the yield rotation. In a PT connection with WHPs, $\theta_{\mathrm{y}}$ and $\theta_{\text {pra }}$ are defined as the connection rotations at which the first WHP yields and the first fracture of WHP occurs, respectively.

Since $\delta=\mathrm{d} \theta$ is the relation that connects the displacement $\delta$ to the rotation $\theta$ of the WHP, where $d$ is the distance of the WHP from the center of rotation, the following relation will hold, namely $\delta_{\mathrm{f}} / \delta_{\mathrm{y}}=\theta_{\mathrm{pra}} / \theta_{\mathrm{y}}=18$. Using this ratio in Eq. (3), the DIF is 1.12 for the SC-MRF.

The DIF in this study is estimated as the ratio of the static over the dynamic force that produces the same dynamic displacement. DIF is depended on the magnification factor $\mu$ as can be seen from Fig. 8 .

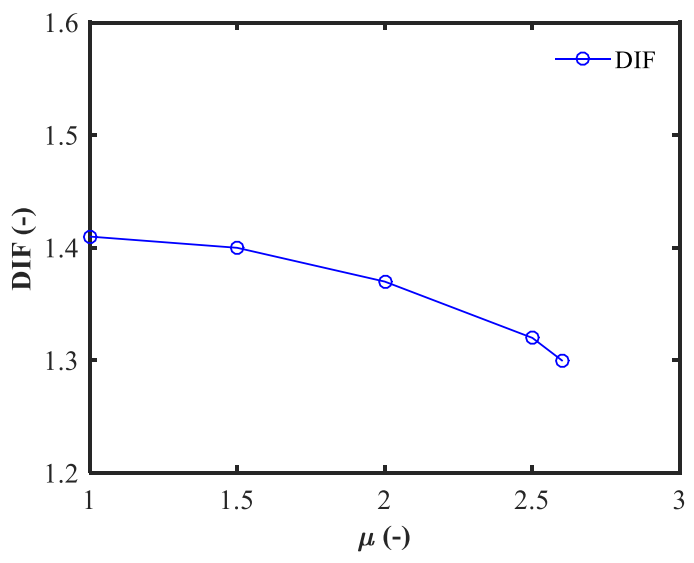

Fig. 8. Dynamic Increased Factor (DIF) in relation to the magnification factor $\mu$.

Comparing this value with the DIF found in the dynamic analyses, which is equal to 1.36 in an average sense, it is concluded that the DIF calculated using Eq. (3) is a non-conservative value to account for the dynamic effects of the progressive collapse in a SC-MRF. More studies on different geometries of SC-MRFs are needed to safely generalize this conclusion.

\section{Conclusions}

This paper evaluate the progressive collapse resistance of a seismic-resistant steel building with self-centering moment resisting frames that employ post-tensioned beam-column connections by numerical analyses performed on a 3D ABAQUS model of the first floor of a prototype building. Simplified and detailed numerical models are developed and validated against experimental results for several components i.e., the composite slab, the fin plate connection and the SC-MRF. Pushdown nonlinear analyses are performed to study the robustness of the building considering the column removal scenario. The results show that the contribution of the composite slab is significant and could overcome the $30 \%$ of the overall progressive collapse resistance of the building. Nonlinear dynamic analyses are performed showing that in this case the dynamic increased factor has values from 1.30 to 1.40. 


\section{Acknowledgements}

This research was supported by a Marie Sklodowska-Curie Action Fellowship within the H2020 European Programme. Any opinions, findings, and conclusions or recommendations expressed in this paper are those of the authors and do not necessarily reflect the views of the European Commission.

\section{References}

[1] Eurocode 8. Design of structures for earthquake resistance. Part 1: General rules, seismic action and rules for Buildings. European Committee for Standardization (CEN). Brussels, Belgium; 2005.

[2] Garlock M, Sause R, Ricles J. Behavior and design of posttensioned steel frame systems. Journal of Structural Engineering 2007;133(3):389-399.

[3] Tzimas AS, Dimopoulos AI, Karavasilis TL. EC8-based seismic design and assessment of self-centering post-tensioned steel frames with viscous dampers, Journal of Constructional Steel Research 2015;105:60-73.

[4] Li Y, Ahuja A, Padgett JE. Review of methods to assess, design for, and mitigate multiple hazards, Journal of Performance of Constructed Facilities; 2012,26 (1):104-117.

[5] Bruneau M, Barbato M, Padgett JE, Zaghi AE, Mitrani-Reiser J, Li Y. State of the Art of Multihazard Design. Journal of Structural Engineering 2017;143(10).

[6] El-Tawil S, Li H, Kunnath S. Computational Simulation of Gravity-Induced Progressive Collapse of Steel-Frame Buildings: Current Trends and Future Research Needs. Journal of Structural Engineering 2014;140(8):1-12.

[7] Vasdravellis G, Baiguera M and Al-Sammaraie D. Robustness assessment of a steel selfcentering moment-resisting frame under column loss. Journal of Constructional Steel Research 2018;141:36-49.

[8] Vasdravellis G, Baiguera M, Al-Sammaraie D. Numerical simulation of the progressive collapse behaviour of steel self-centering moment resisting frames. Eighth International Conference on Steel and Alluminium Structures. Hong Kong, China; 2016.

[9] ABAQUS/Standard and ABAQUS/ExplicitVersion 6.13.1. ABAQUS Theory Manual. Dassult Systems; 2016.

[10]Ding Y, Song X, Zhu HT. Probabilistic progressive collapse analysis of steel-concrete composite floor systems. Journal of Constructional Steel Research 2017;129:129140.
[11] Vasdravellis G, Uy B, Tan EL, Kirkland B. The effects of axial tension on the sagging-moment regions of composite beams. Journal of Constructional Steel Research 2012;72:240-253.

[12] Vasdravellis G, Uy B, Tan EL, Kirkland B. The effects of axial tension on the hogging-moment regions of composite beams. Journal of Constructional Steel Research 2012;68:20-33.

[13] Hognestad E. A study of combined bending and axial load in reinforced concrete members. Bull. Ser. No. 399. University of Illinois at UrbanaCampaign, College of Engineering, Engineering Experiment Station. Urbana, IL; 1951.

[14]Eurocode 2: Design of concrete structures - Part 1-1: General rules and rules for Buildings. European Committee for Standardization; 2004.

[15]Eurocode 4: Design of composite steel and concrete structures - Part 1-1: General rules and rules for Buildings. European Committee for Standardization; 2004.

[16] Thompson SL. Axial, shear and moment interaction of single plate 'shear tab' connections. MS thesis, Milwaukee School of Engineering. Milwaukee; 2009.

[17] Main JA, Sadek F. Modeling and Analysis of Single-Plate Shear Connections under Column Loss. Journal of Structural Engineering 2014;140(3).

[18] Eurocode 3: Design of steel structures - Part 1-8: Design of joints. European Committee for Standardization; 2003.

[19] Vasdravellis G, Karavasilis TL, Uy B. Finite element models and cyclic behavior of selfcentering steel post-tensioned connections with web hourglass pins. Engineering Structures 2013;52:1-16.

[20] DoD. Unified Facilities Criteria (UFC) Design of Buildings to Resist Progressive Collapse; 2009. 